OPEN ACCESS

Edited by:

Ying Ma,

University of Coimbra, Portugal

Reviewed by:

Gabor Jakab,

University of Pecs, Hungary Bernard R. Glick,

University of Waterloo, Canada

*Correspondence:

Prabhat N. Jha,

Department of Biological Science,

Birla Institute of Technology and

Science (BITS) Pilani, FD-III, Pilani

333031, Rajasthan, India

prabhatn.jha@gmail.com;

prabhatjha@pilani.bits-pilani.ac.in

Specialty section:

This article was submitted to

Plant Biotic Interactions,

a section of the journal

Frontiers in Microbiology

Received: 27 April 2015

Accepted: 24 August 2015

Published: 09 September 2015

Citation:

Singh RP, Shelke GM, Kumar A and Jha PN (2015) Biochemistry and genetics of ACC deaminase: a weapon to "stress ethylene" produced in plants. Front. Microbiol. 6:937. doi: 10.3389/fmicb.2015.00937

\section{Biochemistry and genetics of ACC deaminase: a weapon to "stress ethylene" produced in plants}

\author{
Rajnish P. Singh ${ }^{1}$, Ganesh M. Shelke ${ }^{2}$, Anil Kumar ${ }^{2}$ and Prabhat N. Jha ${ }^{1 *}$ \\ ${ }^{1}$ Department of Biological Sciences, Birla Institute of Technology and Science (BITS) Pilani, Pilani, India, ${ }^{2}$ Department of \\ Chemistry, Birla Institute of Technology and Science (BITS) Pilani, Pilani, India
}

1-aminocyclopropane-1-carboxylate deaminase (ACCD), a pyridoxal phosphate-dependent enzyme, is widespread in diverse bacterial and fungal species. Owing to ACCD activity, certain plant associated bacteria help plant to grow under biotic and abiotic stresses by decreasing the level of "stress ethylene" which is inhibitory to plant growth. ACCD breaks down ACC, an immediate precursor of ethylene, to ammonia and $\alpha$-ketobutyrate, which can be further metabolized by bacteria for their growth. ACC deaminase is an inducible enzyme whose synthesis is induced in the presence of its substrate ACC. This enzyme encoded by gene AcdS is under tight regulation and regulated differentially under different environmental conditions. Regulatory elements of gene AcdS are comprised of the regulatory gene encoding LRP protein and other regulatory elements which are activated differentially under aerobic and anaerobic conditions. The role of some additional regulatory genes such as AcdB or LysR may also be required for expression of AcdS. Phylogenetic analysis of AcdS has revealed that distribution of this gene among different bacteria might have resulted from vertical gene transfer with occasional horizontal gene transfer (HGT). Application of bacterial AcdS gene has been extended by developing transgenic plants with ACCD gene which showed increased tolerance to biotic and abiotic stresses in plants. Moreover, distribution of ACCD gene or its homolog's in a wide range of species belonging to all three domains indicate an alternative role of ACCD in the physiology of an organism. Therefore, this review is an attempt to explore current knowledge of bacterial ACC deaminase mediated physiological effects in plants, mode of enzyme action, genetics, distribution among different species, ecological role of ACCD and, future research avenues to develop transgenic plants expressing foreign AcdS gene to cope with biotic and abiotic stressors. Systemic identification of regulatory circuits would be highly valuable to express the gene under diverse environmental conditions.

Keywords: ACC, AcdS, ethylene, abiotic stress, PGPR 


\section{Introduction}

Plant growth and productivity are limited by several physiological and environmental factors that include availability of macro and micronutrients, physical and chemical properties of soil, plant genotype and growth conditions. Apart from these factors, plant growth and yield are detrimentally affected by diverse biotic and abiotic factors. The latter include stressors such as salt, low and high temperature, drought, water logging, mechanical wounding, the presence of heavy metals and other organic and inorganic toxic compounds (Gamalero and Glick, 2012). The loss incurred due to these factors is estimated to be $>50 \%$ for most major crop plants (Boyer, 1982; Bray et al., 2000). Thus, abiotic stresses are the major factors that adversely affect the agricultural productivity worldwide. Therefore, world food production needs to be doubled to cope with the ever-growing demand of the population (Tilman et al., 2002). Problems of biotic and nutritional factors can be overcome using pesticides and biofertilizers, respectively but getting rid of calamities arose due to abiotic factors by non-biological means is highly challenging.

Plants respond to above-mentioned stressors by modulating the level of various hormones which in turn induce expression of stress-related proteins required for protection from the deleterious effects of stressors. One of the most common plant hormone that mediates response to the stressors is ethylene. However, when ethylene is produced more than its threshold level, it turns out as "stress ethylene" which is unfavorable in terms of root/shoot proliferation and other growth parameters and, thus hinders plant growth and development. Effect of stress ethylene in plants can be reduced by certain plant-associated bacteria that possess an enzyme 1-aminocyclopropane-1-carboxylate deaminase (ACCD) (Glick, 2007). ACCD breaks down ACC, an immediate precursor of ethylene, to $\alpha$-ketobutyrate and ammonia resulting into decrease in level of ethylene in plants which in turn resumes root/shoot growth (Honma and Shimomura, 1978; Glick, 2014). This property of attributing tolerance to abiotic stressors by ACCD activity and some additional mechanisms of plant growth promoting bacteria (PGPB) to ameliorate stresses in host plants are referred as "induced systemic tolerance" (Yang et al., 2009). Thus, PGPB equipped with ACCD activity are of utmost importance in reducing the deleterious effect of environmental stressors (Table 1). It has been established that generation of stress ethylene is central to the effect of various stressors in plants. Therefore, the present review addresses importance of ethylene in plant physiology, details of biochemistry and genetics of ACC deaminase which reduces the level of stress ethylene in plants and relieve from the deleterious effect of environmental stressors.

\section{Ethylene Biosynthesis and Role in Plant Physiology}

The ethylene production in plants depends on the environmental condition as well as the severity of various stresses. The recognition of ethylene as a plant growth regulator originated from observation of premature shedding of leaves, geotropism of etiolated pea seedling when exposed to illuminating gas, and ripening of oranges when exposed to gas from kerosene combustion (Pierik et al., 2006; Glick, 2007). Further studies with the analytical techniques like gas chromatography (GC) elaborated its role in plant growth and development. Ethylene at optimal concentration $\left(10 \mathrm{~g} \mathrm{~L}^{-1}\right)$ is essential in functions related to normal growth and development in plants such as formation of adventitious root and root hairs, acceleration of seed germination, breaking seed dormancy etc. (Arshad and Frankenberger, 1990; Jackson, 1991). However, at a higher concentration $\left(25 \mathrm{~g} \mathrm{~L}^{-1}\right)$, it induces defoliation, inhibition of root elongation, inhibition of nodulation in legumes, leaf senescence, leaf abscission, chlorophyll destruction, and epinasty. Therefore, it is imperative to regulate the ethylene production in roots for normal growth and development of the plants.

The ethylene biosynthesis begins with enzyme ACC synthase that converts S-adenosylmethionine (SAM) to 1-aminocyclopropane-1-carboxylic acid (ACC) and 5'methylthioadenosine (MTA) latter of which is recycled to L-methionine. The next step is the conversion of ACC to ethylene by ACC oxidase. Several isoforms of ACC oxidase has been reported that show differential activity under different physiological conditions (Abeles et al., 1992). Synthesis of ethylene is affected by a number of different factors including temperature, light, nutrition, gravity, and the presence of various types of biological stressors to which the plant may be subjected (Glick, 2007). Regarding a plant's response to stress, an increased level of ethylene is formed in response to the presence of metals, organic and inorganic chemicals, extreme temperature, ultraviolet light, insect attack, phytopathogens (bacteria and fungi), and mechanical wounding. A model proposed for the synthesis of stress ethylene suggests that two peaks of ethylene are observed after stress exposure to plants. The first small peak of ethylene (Robison et al., 2001; Van Loon et al., 2006; Desbrosses et al., 2009) is believed to be responsible for transcription of genes that encode the plant defensive/protective proteins. The second much larger ethylene peak, termed as "stress ethylene" emerged in response to stresses is detrimental to plant growth and initiates processes like senescence, chlorosis and leaf abscission (Glick, 2007). Reduction in the level of stress ethylene by any chemical or biological treatment can significantly lower the magnitude of stress ethylene and decrease stress-induced damage to the plants (Van Loon et al., 2006). As mentioned above, one of the most common and effective mechanisms to reduce the level of stress ethylene is ACCD mediated degradation of ACC. Following sections deal with functioning and molecular aspects of ACC deaminase.

\section{ACC Deaminase: Biochemical Properties and Mode of Action}

ACC deaminase was first discovered in soil microorganism and shown to convert ACC to ammonia and $\alpha$-ketobutyrate, both of which further metabolized by a microorganism (Honma and Shimomura, 1978). It is a pyridoxal phosphate-dependent 
TABLE 1 | PGPR containing ACC deaminase mediated protection in response to various types of stresses.

\begin{tabular}{|c|c|c|c|}
\hline Bacteria & Host plant & Stress protection & References \\
\hline Achromobacter piechaudii ARV8 & Lycopersicon esculentum & Salt & Mayak et al., 2004 \\
\hline Alcaligenes sp., Bacillus pumilus & Brassica napus & Heavy metals & Belimov et al., 2001 \\
\hline Burkholderia sp. J62 & Lycopersicon esculentum & Lead & Jiang et al., 2008 \\
\hline B. phytofirmans PsJN & Vitis vinifera & Low temperature & Ait Bakra et al., 2006 \\
\hline Enterobacter aerogenes NBRIK24 & Brassica juncea & Fly-ash soil & Kumar et al., 2008 \\
\hline Kluyvera ascorbata SUD165 & Brassica napus & Nickel & Burd et al., 1998 \\
\hline K. ascorbata SUD165/26 & Lycopersicon esculentum & Lead & Burd et al., 2000 \\
\hline Pseudomonas putida UW4 & Lycopersicon esculentum & Flooding & Grichko and Glick, 2001 \\
\hline P. fluorescens YsS6 & Lycopersicon esculentum & Salt & Ali et al., 2014 \\
\hline Pseudomonas putida & Vigna radiata & Salt & Mayak et al., 1999 \\
\hline P. fluorenscens $\mathrm{CHAO}$ & Solanum tuberosum & Plant pathogen & Wang et al., 2000 \\
\hline P. fluorenscens CHA96 & Cucumis sativus & Plant pathogen & Wang et al., 2000 \\
\hline P. putida UW4 & Pinus sabiniana & Plant pathogen & Nascimento et al., 2013 \\
\hline P. putida UW4, P. putida HS-2 & Brassica napus & Nickel & Farwell et al., 2007 \\
\hline P. fluorescens ACC-5 & Pisum sativum & Drough & Zahir et al., 2008 \\
\hline Pseudomonas sp. & Pisum sativum & Drough & Arshad et al., 2008 \\
\hline Sinorhizobium sp. Pb002 & Brassica juncea & Lead & Di Gregorio et al., 2006 \\
\hline Variovorax paradoxus & Brassica juncea & Cadmium & Belimov et al., 2005 \\
\hline
\end{tabular}

enzyme and approximately $3 \mathrm{~mol}$ of enzyme-bound pyridoxal phosphate per mol of an enzyme or $1 \mathrm{~mol}$ per trimeric subunit (Honma, 1985) are required for enzyme activity. ACC deaminase was first purified from Pseudomonas sp. strain ACP and partially purified from Pseudomonas chloroaphis 6G5 (Klee et al., 1991) and Pseudomonas putida GR12-2 (Jacobson et al., 1994). Enzyme purified from all three sources appears to have similar molecular mass and form. The native size of 110-112 KDa has been reported from Pseudomonas sp. strain ACP and $105 \mathrm{KDa}$ for the enzyme from $P$. putida GR12-2. The enzyme is trimeric in form and has an approximate subunit mass of 36,500 daltons.

The absorption spectra of purified ACC deaminase from Pseudomonas sp. show different absorption maxima at 416 and $326 \mathrm{~nm}$ at $\mathrm{pH} 6$ and $\mathrm{pH}$ 9, respectively (Honma, 1985). It is possible that the $326 \mathrm{~nm}$ band seen at $\mathrm{pH} 9$ is the active form of ACC deaminase to which substrates and inhibitors bind (Honma, 1985; Jacobson et al., 1994). The observed $\mathrm{K}_{\mathrm{m}}$ value of enzyme extracts of different microorganisms at $\mathrm{pH} 8.5$ fall in the range of 1.5-17.4 $\mathrm{mM}$, indicating the low affinity of the enzyme for ACC. The overall efficiency $\left(\mathrm{k}_{\mathrm{cat}} / \mathrm{k}_{\mathrm{m}}\right)$ of ACC deaminase is approximately $690 \mathrm{M}^{-1} \mathrm{~S}^{-1}$ following the second order kinetics. The $\mathrm{K}_{\mathrm{m}}$ value of ACC deaminase for ACC has been estimated for enzyme extracts of microorganism at $\mathrm{pH} 8.5$ (Klee et al., 1991). Enzyme activity of ACCD was evaluated over a wide range of $\mathrm{pH}$ in many bacterial species, and the highest activity was observed at $\mathrm{pH}$ 8.0-8.5 (Zhao et al., 2003). The optimal temperature for ACC deaminase activity of $P$. putida GR $12-2$ is $30^{\circ} \mathrm{C}$ (Glick et al., 1998).
ACC deaminase is an inducible enzyme whose synthesis is induced in the presence of its substrate ACC. The minimum level of the substrate for induction was measured as $100 \mathrm{nM}$ in Pseudomonas sp. strain ACP and P. putida GR12-2. The induction of ACCD is a complex and slow process. It exhibits activity within the first few hours of induction with the substrate, but the activity decreases gradually after initial induction (Walsh et al., 1981; Jacobson et al., 1994). The basal level of enzyme activity is observed in minimal medium supplemented with ammonium sulfate as a nitrogen source. Honma (1983) demonstrated the induced activity after switching the bacteria from nutrient rich medium to minimal medium supplemented with ACC as sole nitrogen source. It illustrates that the induction of enzyme activity is directly correlated with substrate ACC. Apart from ACC, other amino acids such as L-alanine, DL-alanine, D-serine also induce enzyme activity and induce expression of ACCD to some extent. Moreover, the induced level of enzyme activity by both ACC and aminoisobutyric acid was observed to be same in Pseudomonas sp. strain ACP (Honma, 1983). Glick et al. (1998) proposed a model for functioning of bacterial ACC deaminase which states that a significant portion of ACC is exuded from plant roots or seeds, taken up by the soil microbes and hydrolyzed to ammonia and $\alpha$-ketobutyrate. The uptake and hydrolysis of ACC decrease the amount of ACC outside the plant roots. Furthermore, the equilibrium between the internal and external ACC level is maintained through exudation of more ACC into the rhizosphere. Thus, decrease in the level of ACC affects biosynthesis of the stress hormone 
ethylene in host plants and stimulate plant growth (Honma et al., 1993; Glick et al., 1998).

Opening of cyclopropane ring of ACC is the main feature of the reaction catalyzed by ACC deaminase. Although the reaction mechanism is not fully understood, nucleophilic addition, and elimination appears to be the most likely routes by which cyclopropane bond is cleaved (Walsh et al., 1981; Ortíz-Castro et al., 2009). ACC deaminase is competitively inhibited by Lisomers of the amino acids such as L-alanine, L-serine, Lhomoserine, and L- $\alpha$ aminobutyric acid where the strongest inhibition is seen with L-alanine and L-serine. ACC related compounds such as 2-alkyl -ACC and vinyl-ACC can also function as substrates for ACC deaminase, purified from Pseudomonas sp. Strain ACP but the enzyme shows an unusual specificity for D-amino acids and is inactive with any of the Lamino acids or their derivatives (Walsh et al., 1981; Honma, 1985). NMR studies showed that a proton is eliminated from the $\alpha$-carbon of $\mathrm{D}$-alanine but not from its $\mathrm{L}$-isomer. These findings explain the deamination of D-amino acids and of several $\beta$ - substituted D-alanines by ACC deaminase and are consistent with the stero-specific cleavage of the cyclopropane ring during ACC deamination (Honma et al., 1993). In the presence of D-alanine, ACC deaminase is inactivated more effectively by the iodoacetamide derivative $1,5 \mathrm{~N}$-iodoacetamidoethyl1-aminonapthalene-5-sulfonic acid (1,5-I- AEDANS) than by iodoacetamide. During inactivation, two residues are modified, a thiol group in cysteine residue 162 and the aldimine bond of pyridoxal phosphate with lysine residue 51 (Honma et al., 1993).

\section{Insight into ACC Deaminase Catalyzed Reaction}

Based on three-dimensional structures, pyridoxal phosphate enzymes have been classified into four major types: (a) Tryptophan synthase, (b) aspartate aminotransferase, (c) Damino acid aminotransferase, and (d) alanine racemase. ACC deaminase is a member of pyridoxal 5-phosphate (PLP) dependent enzymes fitting into the tryptophan synthase family. PLP enzymes catalyze a wide range of metabolic reactions such as transamination, deamination, decarboxylation, and eliminations of $\beta$ and $\gamma$ substituent groups. The reaction catalyzed by ACC deaminase differs from other PLP-dependent enzymes as the ring cleavage cannot proceed through $\alpha$-carbanionic intermediate due to lack of abstractable $\alpha$-hydrogen atom from the substrate ACC. Two types of reactions can be catalyzed by ACC deaminase for a breakdown of ACC. First, abstraction of hydrogen atom and opening of cyclopropane ring by $\mathrm{Lys}^{51}$ mediated series of hydrolytic reactions and second, opening of cyclopropane ring by nucleophilic attack on $\beta$-carbon atom of ACC followed by $\beta$ proton abstraction at the pro- $\mathrm{R}$ carbon by a basic residue Lys ${ }^{51}$ (Zhao et al., 2003).

The mechanistic action of ACCD on its substrate is depicted in Figure 1. The substrate ACC reacts with internal aldimine $[\mathrm{A}]$ resulted from the reaction of PLP (Pyridoxal 5-phosphate) cofactor with Lys residue of ACC deaminase enzyme. This leads to conversion of internal aldimine to external aldimine $[\mathrm{C}]$ via aminyl intermediate $[\mathrm{B}]$ known as trans-aldimination process. These initial mechanistic routes are shared between both proposed mechanisms, i.e., (a) Direct $\beta$ hydrogen abstraction and (b) Nucleophilic addition followed by $\beta$-hydrogen abstraction.

Ose et al. (2003) proposed that Lys ${ }^{51}$ residue of ACCD causes an initial direct $\beta$-hydrogen abstraction of the methylene proton leading to the formation of a quinonoid [1] (Figure 1, Route I). The quinonoid [1] undergoes further electronic rearrangement and protonation to form another quinonoid [2]. This is followed by nucleophilic attack by a basic residue on the protein backbone, which ultimately produces 2 -aminobut-2-enoate and a quinonoid [3]. These products reversibly undergo hydrolysis to form 2-oxobutanoate and ammonium, regenerating the internal aldimine. In route II, steps are identical to those proposed for the route I up to the production of external aldimine [C] (Figure 1, Route II). Ring opening is initiated by nucleophilic attack of a basic residue of protein on the pro-S $\beta$-carbon of ACC and a nearby second basic residue located on the protein. It follows the removal of a proton from the pro- $\mathrm{R} \beta$ carbon of ACC which results in the formation of a quinonoid. The remaining mechanistic steps are identical to those of the first mechanism (Figure 1, Route II).

\section{Prevalence of ACC Deaminase}

The presence of ACC deaminase has been reported in all three domains, i.e., eukarya, bacteria, and archaea. However, ACC deaminase activity is known to be present majorly in different species of bacteria and in some fungi (Table 2). ACCD activity has been found in a wide range of gram positive and gram negative bacteria (Nascimento et al., 2014). It has also been reported in strains of Pyrococcus horikoshii (Fujino et al., 2004), a hyperthermophilic archaeon. Among eukaryotes, production of ACCD is well evident in some fungi, which include a few species of yeast such as Hansenula saturnus (Minami et al., 1998), Issatchenkia occidentalis (Palmer et al., 2007), other fungal species namely Penicillium citrinum and Trichoderma asperellum, and a stramnopile, Phytophthora sojae (Jia et al., 1999; Viterbo et al., 2010; Singh and Kashyap, 2012). Recently, ACCD activity has also been observed in certain plants such as Arabidopsis thaliana, poplar, and tomato plant (McDonnell et al., 2009; Plett et al., 2009). Presence of ACCD has been confirmed at the molecular level by amplification and sequence analysis of $A c d S$, a structural gene encoding ACCD. The AcdS gene is commonly found in Actinobacteria, Deinococcus-Thermus, three classes of Proteobacteria $(\alpha, \beta$, and $\gamma$ ), various fungi belonging to Ascomycota and Basidiomycota, and in some Stramenopiles. Although, the presence of ACCD activity has been demonstrated in bacteria belonging to phyla Chlorobi, Bacteroidetes, and Firmicutes but the genes corresponding to ACCD have not been reported yet (Nascimento et al., 2014). On the contrary, putative AcdS genes have been reported in Meiothermus and Phytophthora based on the sequence similarity but there is no record of ACC deaminase activity in these thermophilic strains.

We analyzed the prevalence of $A c d S$ gene in IMG (Integrated microbial genomes) database (http://img.jgi.doe.gov/) from Joint 


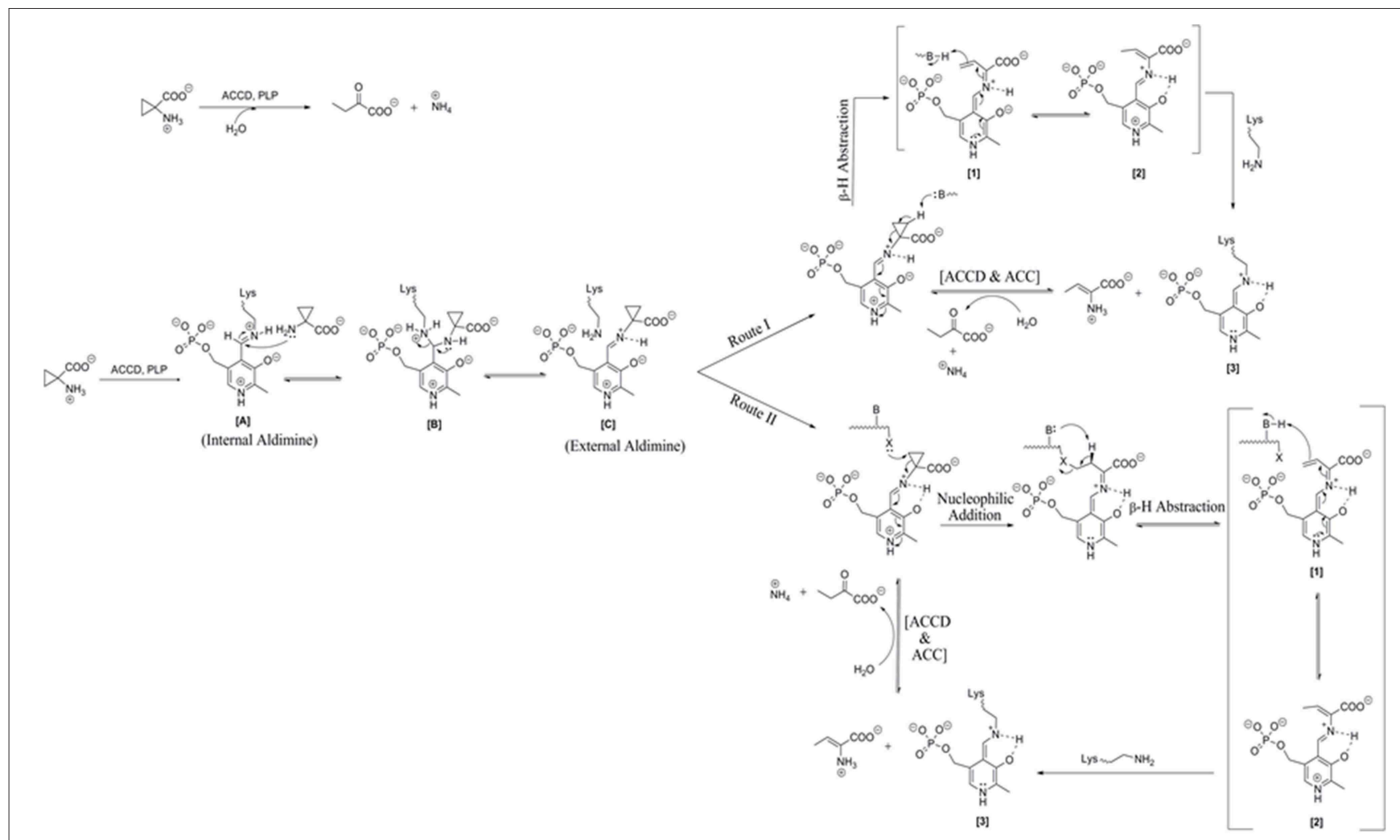

FIGURE 1 | Reaction mechanism catalyzed by microbial ACC deaminase. Route I: direct $\beta$-H (Hydrogen) abstraction, Route II: Addition of nucleophiles followed by $\beta-\mathrm{H}$ (Hydrogen) abstraction. Modified figure adapted from the source ref. Hontzeas et al. (2006).

genome Institute (JGI) using locus tag search corresponding to $A c d S$ of $P$. putida UW4. The AcdS sequences having more than $1000 \mathrm{bp}$ were chosen for further analysis. Altogether, 485 strains belonging to different genera including Acidovorax, Bordetella, Brenneria, Burkholderia, Collimonas, Cupriavidus, Curvibacter, Dickeya, Herbaspirillum, Halomonas, Lonsdalea, Methylibium, Pantoea, Phytophthora, Polaromonas, Pseudomonas, Ralstonia, Serratia, Tatumella, Variovorax, and Xenophilus, showed presence of $A c d S$ gene. Important species belonging to these genera are listed in Supplementary Table 1. These data were extracted from the genomic sequences of organisms from different ecological niches including a human host, bulk soil, plants, and water. For the presence of gene encoding ACCD in other domains (eukarya and archaea), gene search was conducted using the product name as a criterion for the search. It revealed that very few members of archea showed the presence of ACCD gene. It includes strains of Archaeoglobus fulgidus, Pyrococcus abyssi, Pyrococcus furiosus, and Thermococcus nautili. Analysis of metagenomic database revealed the presence of genes encoding ACCD in various kingdoms, i.e., animalia, chromalveolate, fungi, and plantae of domain Eukarya (Table 3). It suggested that among domain Eukarya, ACCD gene is prevalent in members of phylum Ascomycota and Basidiomycota. The IMG database extends our knowledge of the existence of ACCD gene in other higher plants from kingdom plantae which include soybean, potato, maize, and castor oil plants. The presence of ACCD encoding genes in several members of kingdom Animalia seems to be intriguing as no obvious role of ACCD in animals is known (Table 3). The presence of ACCD gene in some pathogenic bacteria associated with human and other animals indicates that ACCD may be required for some other unknown function or these bacteria may earlier be plant-associated which later on evolved to colonize animals and other kingdoms as well. Moreover, both bacterial and fungal ACC deaminase shares a common origin and belongs to pyridoxal phosphate-dependent enzyme related to tryptophan-synthase family.

\section{Genetics and Expression of ACC Deaminase}

\section{ACC Deaminase Gene}

Gene AcdS encoding ACC deaminase have been detected in several bacterial and fungal genera as discussed above. More recently, ACC deaminase has been found in wide range of gram-negative bacteria (Belimov et al., 2001; Wand et al., 2001; Hontzeas et al., 2004; Tak et al., 2013), Gram-positive bacteria (Belimov et al., 2001; Timmusk et al., 2011), rhizobia (Ma et al., 2003b; Uchiumi et al., 2004), endophytes (Sessitsch et al., 2002; Rashid et al., 2012), and fungi (Jia et al., 1999). Putative ACC deaminase gene have also been reported several species including $R$. leguminosarum bv. Trifoli (Itoh et al., 1996) and 
TABLE 2 | List of microorganism with ACC deaminase activity.

\begin{tabular}{|c|c|c|}
\hline Strain & $\begin{array}{c}\text { ACCD activity } \\
\text { (nmol } \alpha-\mathrm{KB} \\
\left.\mathrm{mg}^{-1} \mathrm{~h}^{-1}\right)\end{array}$ & References \\
\hline Achromobacter xylosoxidans A551 & 400 & Belimov et al., 2005 \\
\hline Acidovorax facilis & 0.0007 & Belimov et al., 2005 \\
\hline A. facilis $4 p-6$ & 3080 & Belimov et al., 2001, 2005 \\
\hline A. xylosoxidans AF302097 & 151 & Belimov et al., 2001 \\
\hline A. xylosoxidans Bm1 & 90 & Belimov et al., 2005 \\
\hline Alcaligenes sp. AF288728 & 1172 & Belimov et al., 2001 \\
\hline A. xylosoxidans AF302096 & 555 & Belimov et al., 2001 \\
\hline A. xylosoxidans AF288734 & 305 & Dell'Amico et al., 2008 \\
\hline Bacillus pumilus AF288735 & 760 & Belimov et al., 2001 \\
\hline Burkholderia caryophylli & 598 & Shaharoona et al., 2007b \\
\hline Enterobacter cloaceae & 295 & Nadeem et al., 2010 \\
\hline E. aerogenes & 341 & Nadeem et al., 2007 \\
\hline Escherichia coli DH5a/p4U2 & 285 & Shah et al., 1998 \\
\hline Flavobacterium ferrugineum & 405 & Nadeem et al., 2007 \\
\hline Methylobacterium sp. & 94 & Madhaiyan et al., 2006 \\
\hline Mycobacterium sp. & 1.14 & Dell'Amico et al., 2008 \\
\hline Pseudomonas aeruginosa & 153 & Zahir et al., 2009 \\
\hline P. bathycetes & 501 & Nadeem et al., 2007 \\
\hline P. brassicacearum AY007428 & 972 & Belimov et al., 2001 \\
\hline P. chlororaphis & 456 & Nadeem et al., 2007 \\
\hline P. fluorescens & 421 & Nadeem et al., 2007 \\
\hline P. fluorescens ATCC 17400/pkK-ACC & 157 & Shah et al., 1998 \\
\hline P. fluorescens TDK1 & 349 & Zahir et al., 2009 \\
\hline P. fluorescens biotype $\mathrm{G}$ & 490 & Shaharoona et al., 2006a \\
\hline P. fluorescens biotype $\mathrm{F}$ & 342 & Zahir et al., 2008 \\
\hline P. oryzihabitans AF288732 & 890 & Belimov et al., 2001 \\
\hline P. syringae & 440 & Nadeem et al., 2007 \\
\hline P. tolaasii & 1.16 & Dell'Amico et al., 2008 \\
\hline Rhizobium hedysari ATCC 43676 & 20 & Ma et al., 2003b \\
\hline R. leguminosarum128C53K & 5 & Belimov et al., 2001, 2005 \\
\hline R. leguminosarum 99A1 & 430 & Ma et al., 2003a \\
\hline Rhodococcus sp. AF 288731 & 833 & Belimov et al., 2001 \\
\hline Rhodococcus sp. strain Fp2 & 7320 & Belimov et al., 2001, 2005 \\
\hline Rhodococcus sp. strain 4N-4 & 12,970 & Belimov et al., 2001, 2005 \\
\hline Serratia ficaria & 326 & Nadeem et al., 2010 \\
\hline S. proteamaculans & 276 & Zahir et al., 2009 \\
\hline S. quinivirans SUD165 & 12 & Belimov et al., 2001, 2005 \\
\hline Variovorax paradoxus 3P-3 & 3700 & Belimov et al., 2001, 2005 \\
\hline V. paradoxus 5C-2 & 4322 & Belimov et al., 2001, 2005 \\
\hline V. paradoxus 2C-1 & 3588 & Belimov et al., 2001, 2005 \\
\hline V. paradoxus sp. & 1805 & Belimov et al., 2005 \\
\hline
\end{tabular}

Mesorhizobium loti MAFF303099 (Kaneko et al., 2002). However, the expression level of ACC deaminase varies from one organism to another. Using a universal pair of primers, a segment of AcdS gene has been amplified and analyzed in several environmental isolates (Hontzeas et al., 2005). Several pair of primers has been designed by various researchers to detect the presence of AcdS gene in bacteria (Duan et al., 2009; Jha et al., 2012).
TABLE 3 | Distribution of ACC deaminase in domain Eukarya.

\begin{tabular}{|c|c|c|}
\hline Kingdom & Phylum & Species \\
\hline \multirow[t]{5}{*}{ Animalia } & Porifera & Amphimedon queenslandica \\
\hline & Chordata & $\begin{array}{l}\text { Branchiostoma floridae, Ciona intestinalis, } \\
\text { Oikopleura dioica }\end{array}$ \\
\hline & Annelida & Capitella teleta \\
\hline & Cnidaria & Nematostella vectensis \\
\hline & Placozoa & Trichoplax adhaerens Grell-BS-1999 \\
\hline \multirow[t]{3}{*}{ Chromealveolata } & Haptophyta & Emiliania huxleyi \\
\hline & Stramnopile & $\begin{array}{l}\text { Saprolegnia parasitica, Phytophthora } \\
\text { ramorum }\end{array}$ \\
\hline & Apicomplexa & Theileria annulata \\
\hline \multirow[t]{2}{*}{ Fungi } & Ascomycota & 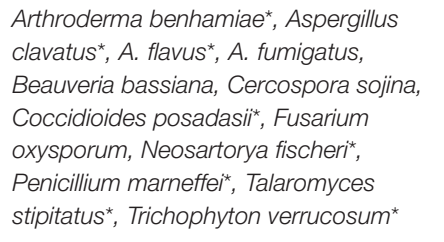 \\
\hline & Basidiomycota & $\begin{array}{l}\text { Cryptococcus neoformans, Gymnopus } \\
\text { luxurians, Schizophyllum commune }\end{array}$ \\
\hline \multirow[t]{3}{*}{ Plantae } & Lycopodiophyta & Selaginella moellendorfii \\
\hline & Magnoliophyta & $\begin{array}{l}\text { Ricinus communis*, Zea mays, Glycine } \\
\text { max, Solanum tuberosum }\end{array}$ \\
\hline & Chlorophyta & Volvox carteri \\
\hline
\end{tabular}

*Putative proteins have been found.

Complete genetic makeup and function of ACCD gene has been well characterized in only a few bacterial species (Duan et al., 2013). We observed from the data recovered from IMG that nucleotide sequences of $A c d S$ gene is very close to other genes namely dcyD and yedO which encode for another PLPdependent enzyme $\mathrm{D}$-cysteine sulfhydralase. This observation is supported by previous reports where some genes previously identified to encode ACC deaminase were found to encode Dcysteine desulfhydrase activity (Riemenschneider et al., 2005). To differentiate sequences of D-cysteine desulfhydrase from ACC deaminase, Nascimento et al. (2014) analyzed AcdS sequences for key protein residues namely Lys51, Ser78, Tyr295, Glu296, and Leu322, known to be important for ACC deaminase activity using Pseudomonas sp. UW4 as a reference. Any change in residues at given locations were considered likely to represent $\mathrm{D}$-cysteine desulfhydrase.

Except few, AcdS gene in the majority of bacterial species is chromosomal DNA-borne. In symbiotic bacteria M. loti (symbiont of lotus spp.), ACC deaminase gene is associated with the nitrogen fixation genes and might be regulated by NifA which is known to activate nif gene expression in association with the product of $r p o N$ gene (Ma et al., 2003a). Moreover, only a small fraction of putative AcdS gene has been shown to encode active enzyme (Glick et al., 2013).

\section{Regulation of ACC Deaminase}

$A c d S$ is highly regulated and expresses differentially depending on presence or absence of oxygen, concentration of substrate, and 
accumulation of products. Except few, mechanism of regulation of $A c d S$ gene in different bacterial genera is not well understood. A model for the regulation of ACC deaminase gene in $P$. putida UW4 (earlier known as Enterobacter clocae UW4) has been proposed by Li et al. (2000). Regulatory elements for the expression of ACC deaminase gene consist of regulatory gene $A c d R$ located $5^{\prime}$ upstream of ACC deaminase structural gene $(A c d S)$, promoter regions for binding of regulatory proteins like Lrp box for binding of Lrp protein, AcdB box for binding regulatory protein $A c d B$, FNR box for binding of fumarate and nitrate reductase protein and, CRP box for binding of cAMP receptor protein. In the presence of ACC, LRP forms an active octamer that binds to a complex of ACC and another protein $A c d B$ (Cheng et al., 2008). $A c d B$ encodes for the glycerophosphoryl diester phosphodiesterase and form complex with ACC. This triparental complex activates transcription of $A c d S$ by binding to its promoter region ( $\mathrm{Li}$ and Glick, 2001). The role of $A c d B$ in $A c d S$ expression has not been observed in other bacteria characterized for $A c d S$ gene expression. ACC deaminase gene is negatively regulated by leucine which is synthesized from $\alpha$-ketobutyrate, a breakdown product of ACCD catalyzed reaction. As the concentration of leucine increases, it favors formation of inactive LRP dimer form which leads to switching off the transcription of AcdS gene (Figure 2).

Regulatory machinery for AcdS expression varies in different species. Results of IMG database analysis showed that presence of $A c d R$ encoding LRP or its homologous sequences is present in the majority of bacteria. In Bradyrhizobium japonicum USDA 110 and Rhizobium leguminosarum bv. Viciae 128 C53K also, LRP like protein and $\sigma 70$ promoter are involved in regulation of AcdS gene (Kaneko et al., 2002; Ma et al., 2003a). The phylogenetic analysis of $A c d R$ gene suggested that AcdS and $A c d R$ were evolved in a similar manner. In Burkholderia sp. CCGE 1002 and Burkholderia phymatum STM 815, there is no $A c d R$ gene but it has two copies of $A c d S$ gene instead, one on the megaplasmid and other on the second chromosome. These shreds of evidence suggest the genomic rearrangement events or gene insertion event in smaller replicons. Regulatory regions of ACC deaminase gene from some bacteria such as Variovorax parrdoxus 5C2 and Achromobacter xylosoxidans A551 does not contain all these regulatory elements described for $P$. putida UW4.

In $M$. loti, the upstream elements of AcdS and nifH contain nifA1 and nifA2 (regulatory $\mathrm{N}_{2}$ fixing unit) and $\sigma^{54}$ RNA polymerase sigma recognition site. It was assumed that expression of ACC deaminase in $M$. loti required the symbiotic nitrogen fixing regulatory gene nifA2 (Nukui et al., 2006). The nifA2 encoded protein NifA2 interact with $\sigma^{54}$ RNA polymerase favoring $A c d S$ transcription. The nifA1 also affect the transcription of $A c d S$ gene up to some extent. however, its role in the expression of $A c d S$ is not properly understood (Nukui et al., 2006) (Figure 3). The expression of $A c d S$ gene in root nodules reduces the harmful effect of ethylene induced senescence and elevates the concentration of fixed nitrogen in nodules. ACC deaminase activity is generally assayed in free-living conditions but in $M$. loti, the activity was detected only in symbiotic nodules (Uchiumi et al., 2004). Uchiumi et al. (2004) have reported that mlr5932, an up-regulated gene in Bacteroides, encodes ACC deaminase, which is involved in enhancing nodulation in Lotus japonicus plants. It is to be noted that unlike free-living bacteria, ACC deaminase produced by nodule forming Rhizobia does not lower the ethylene level throughout the plant and may not be used to protect plants from various stress. Also, the level of

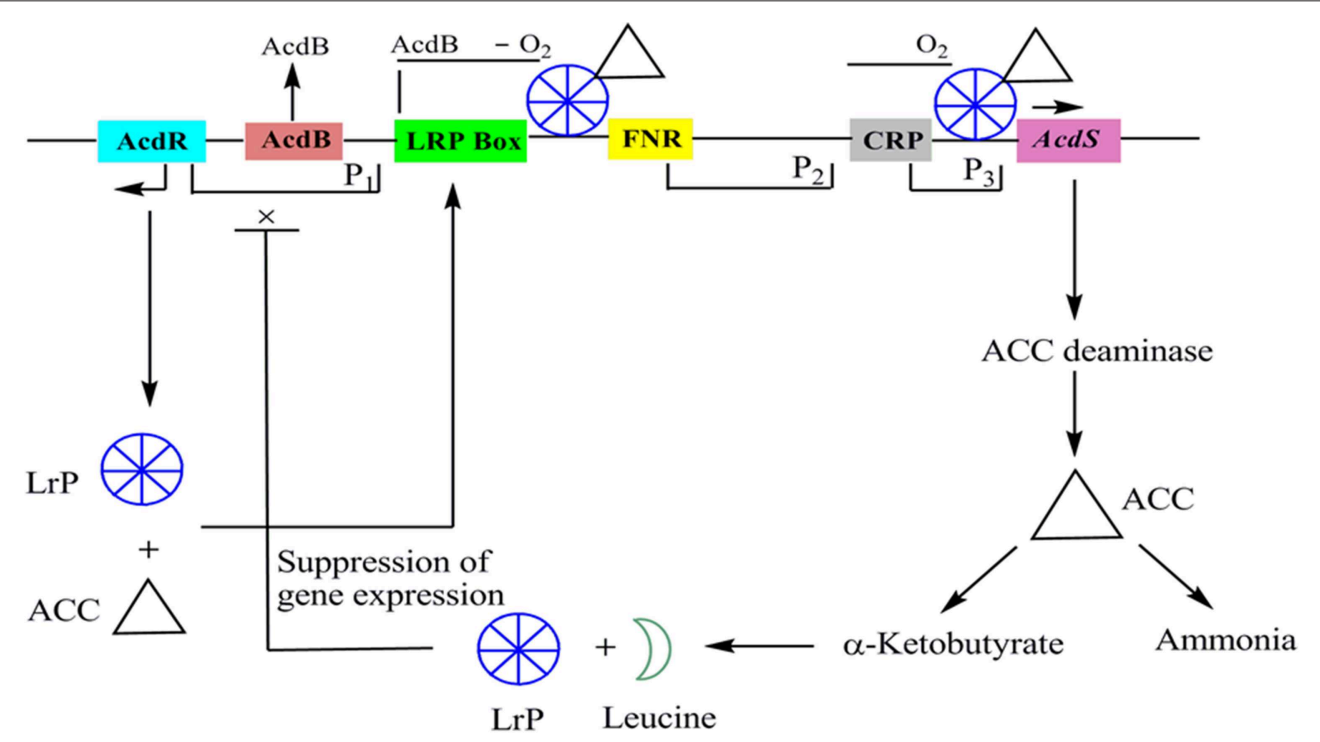

FIGURE 2 | The regulatory circuits of AcdS gene expression in Pseudomonas putida UW4 and other related bacteria. AcdR, regulatory gene for ACC deaminase; AcdB: encoding for glycerophosphoryl diester phosphodiesterase; LRP, Leucine responsive protein; FNR: fumarate nitrate reductase protein; CRP, c-AMP receptor protein; AcdS, gene for encoding ACC deaminase. 


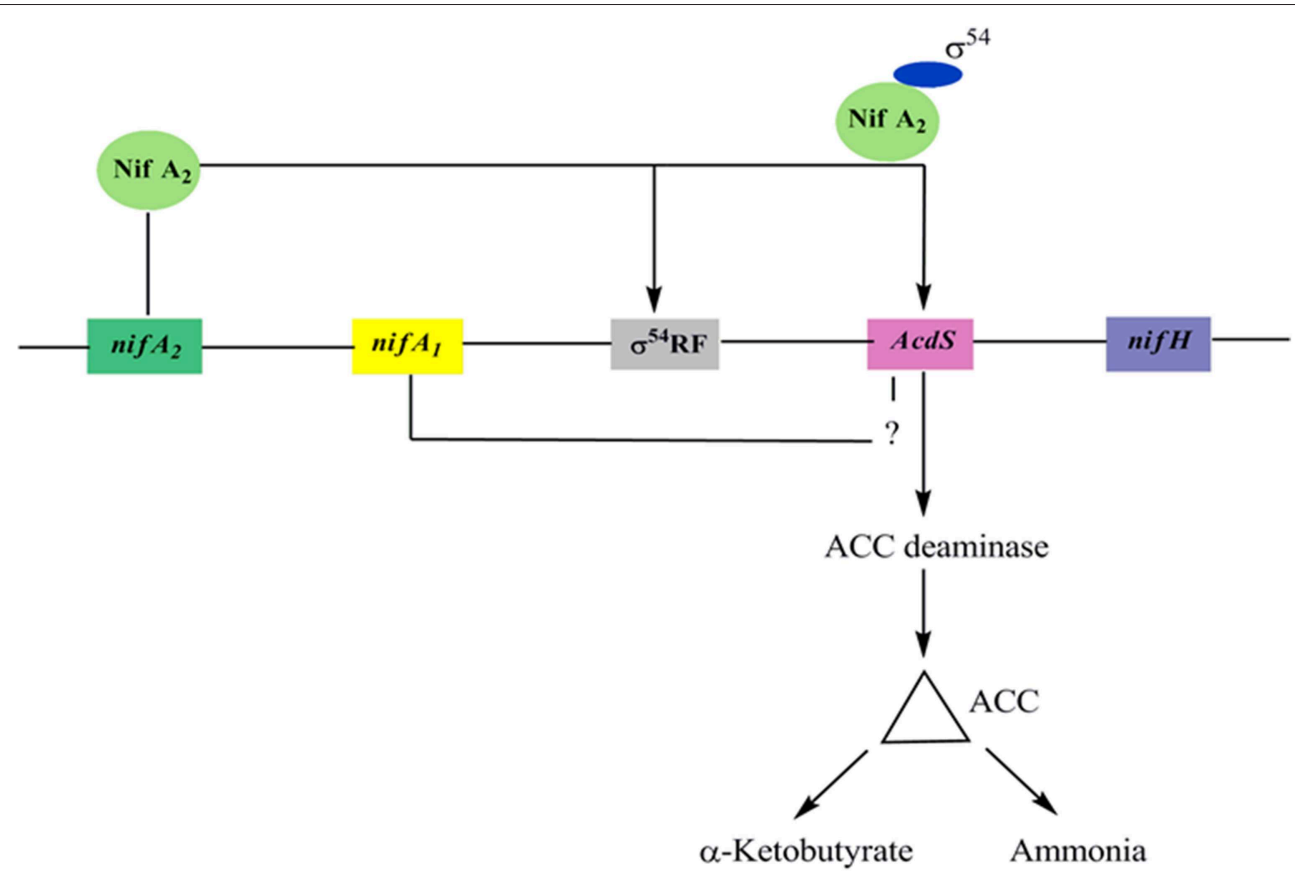

FIGURE 3 | A model for AcdS gene regulation in nitrogen fixing Mesorhizobium sp. Expression of AcdS is positively regulated by Nif $\mathrm{A}_{2}$ protein which binds to $\sigma^{54}$ and switch on transcription of AcdS gene. NifA 1 is also required in regulation of AcdS but its role is not well-understood.

ACCD produced in the nodule is only $2-10 \%$ of ACCD produced by free-living bacteria.

In many Actinobacteria and Meiothermus, GntR protein coding gene is found next to AcdS gene. These evidence indicate a possibility that some downstream elements are also involved in regulation of ACC deaminase expression. In some members of these genera, the absence of promoter region strongly suggests that the interaction of $A c d S$ gene and some downstream element next to $A c d S$ gene is involved in the regulation of $A c d S$ gene transcription. In certain species of Actinobacteria and Proteobacteria like Brenneria sp. EniD312, Burkholderia xenovorans LB4000 and Pantoea sp. At-9B, LysR family of transcription regulatory elements, are found in close vicinity of AcdS gene. However, the exact mechanism of regulation of ACC deaminase in these organisms is still poorly known. Additional genetic and biochemical studies are necessary to understand the mechanism of ACC deaminase regulation and functioning in different bacterial genera.

Putative ACC deaminase gene in M. loti MAFF303099 does not contain any regulatory elements nor display any enzyme activity when it is induced by ACC (Ma et al., 2003b). Expression of ACC deaminase in $R$. leguminosarum bv. viciae $128 \mathrm{C} 53 \mathrm{~K}$ is induced by ACC concentrations as low as $1 \mu \mathrm{M}$ (Ma et al., 2003b). Experimental evidence suggested that introducing ACC deaminase gene as well as its regulatory gene from $R$. leguminosarum bv. Viciae 128C53K to a strain of Sinorhizobium meliloti showed greater efficiency in nodulating Medicago sativa (alfalfa) (Ma et al., 2004) and latter strain was more competitive in nodulation than the wild type (Ma et al., 2004).

\section{Evolution of ACC Deaminase Gene}

Phylogenetic analysis based on $A c d S$ gene and protein sequence from different microbial species has been conducted to study the evolution of ACC deaminase gene. Available sequence data revealed that the most of the ancient bacteria belonging to Actinobacteria and Deinococcus-Thermus possess AcdS gene in their primary and unique chromosome. The AcdS gene in many $\alpha$-proteobacteria is also found in the chromosomal DNA. The presence of AcdS gene has also been observed in plasmid observed on a plasmid DNA in a few bacteria which might have resulted from an event of extensive gene transfer from primary chromosome to plasmid between the members of $\alpha$-proteobacteria. Location of AcdS gene in the second chromosome of Burkholderia and in plasmids of Pseudomonas reflects the intragenomic transfer of AcdS genes from primary chromosome to plasmids. On the other hand, the presence of AcdS gene sequence in some fungi like Fomitopsis pinicola FP-58527 belonging to Basidiomycota suggested having a bacterial origin. The monophyletic origin of ACC deaminase is evident from the conservation of $A c d S$ protein sequences from fungi, Actinobacteria, and $\alpha$-proteobacteria signify. The presence of $A c d S$ gene in some fungal classes and in members of Stramenopiles suggest that horizontal gene transfer (HGT) resulted in the transfer of $A c d S$ not only between bacteria but also between different domains. To gain additional knowledge about the evolution of ACC deaminase gene, multiple AcdS gene sequences and protein sequences were aligned. Based on phylogenetic studies, it was assumed that ACC deaminase belongs to a broader group of pyridoxal phosphate-dependent enzymes that share a common ancestor. It might be possible 
that this enzyme was originated as a consequence of specific mutation in its ancestral enzyme gene (Nascimento et al., 2014). Recently, based on alignment of multiple AcdS sequence from diverse species, Nascimento et al. (2014) inferred that the continuous vertical transmission of $A c d S$ genes might be responsible for the presence of $A c d S$ gene in bacteria that are not associated with ACC producing organism. Our analysis of AcdS using IMG database and subsequent construction of phylogenetic tree also confer that evolution of AcdS gene resulted from vertical gene transfer with occasional HGT. A consensus bootstrap tree was constructed using 465 AcdS sequences obtained from IMG database which showed that accept few, AcdS of similar species clustered together supporting the above inference (Figure 4). However, many earlier studies suggested a role of HGT in the evolution of AcdS gene. Intragenomic AcdS transfer might play a role in HGT transfer as well as the divergence of AcdS gene. Furthermore, these intragenomic transfers may also lead to loss of the gene in many organisms. Phylogenetic analysis of several AcdS gene from ACC deaminase bacteria such as Variovorax paradoxus 5C-2, $V$. paradoxus 3P-3, and Achromobacter spp. indicated that the gene evolved through HGT (Hontzeas et al., 2005). Moreover, the presence of AcdS gene in the symbiotic island of many mesorhizobium spp. like M. loti R7A, M. australicum WSM2073T, M. opportunistum WSM2075T confirms the horizontal transfer of AcdS gene (Nascimento et al., 2012b). Even though most of the phylogenetic studies of AcdS gene has been done on proteobacteria, presence of ACC deaminase enzyme have also been reported in Actinobacteria (Hontzeas et al., 2005), Firmicutes (Ghosh et al., 2003), and Bacteroidetes (Maimaiti et al., 2007).

Prigent-Combaret et al. (2008) reported that like AcdS, $A c d R$ also have evolved through HGT. Owing to horizontal (lateral) gene transfer, the juxta-position of $A c d S$ and $A c d R$ gene has occurred in Agrobacterium tumefaciens d3, B. japonicum USDA 110, R. leguminosarum bv. Viciae 128C53K, A. xylosoxidans A551 (Trott et al., 2001; Kaneko et al., 2002; Hontzeas et al., 2005). However, it is not clear that $A c d R$ gene was inherited along with the AcdS gene or independently. The current knowledge of the phylogeny and evolution of $A c d S$ and $A c d R$ gene is still incomplete. The presence of $A c d R$ in juxta-position to $A c d S$ gene in most proteobacteria acquired through a coupled evolution and transmission of these genes. Therefore, more research is required for elucidating the role of protein encoding genes located in the vicinity to AcdS, which can focus on a different mechanism of ACC deaminase regulation.

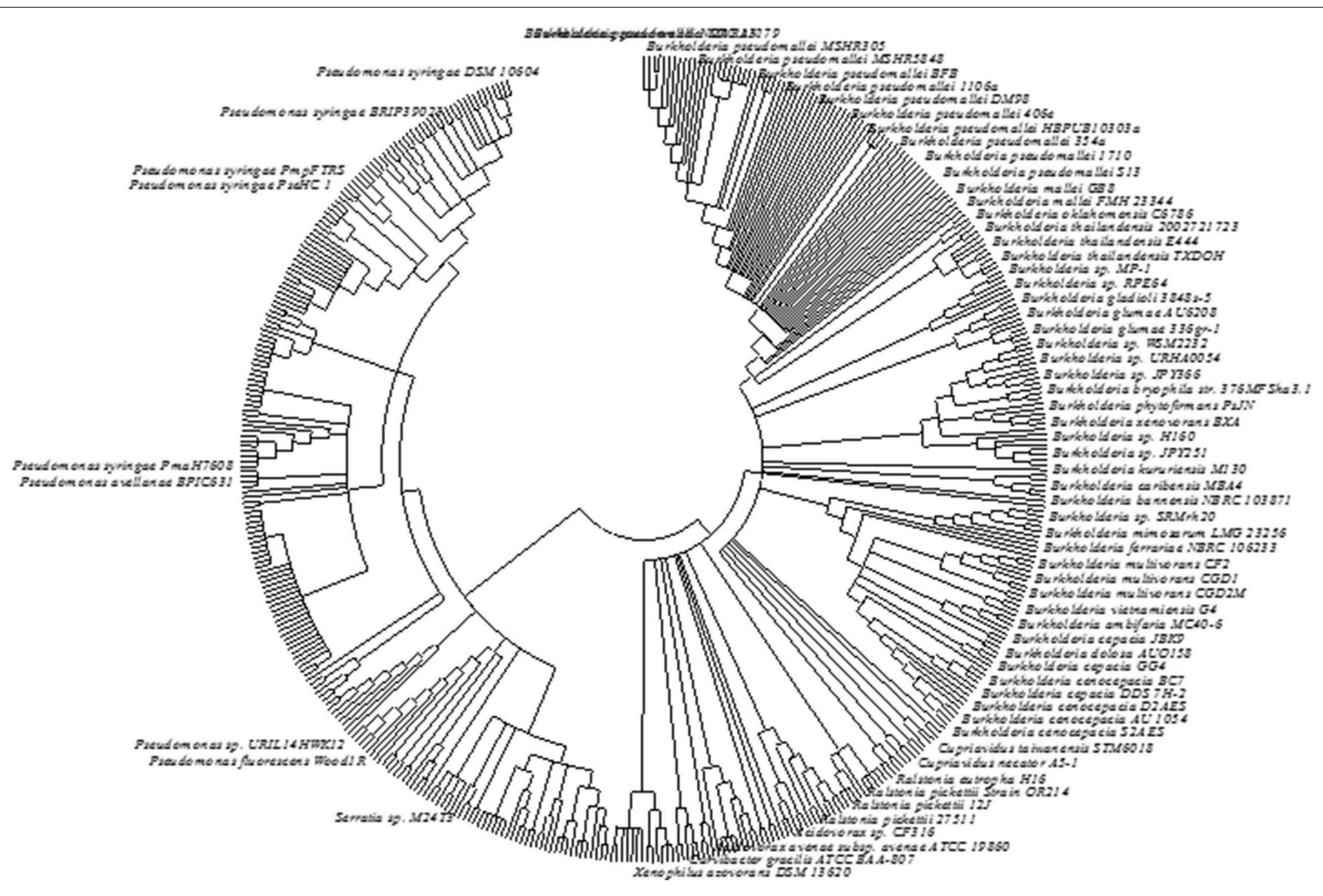

FIGURE 4 | The phylogentic tree constructed from AcdS gene sequence of different bacterial strains. The sequence data obtained from IMG database of JGI were used. The evolutionary history was inferred using the Neighbor-Joining method. The bootstrap consensus tree inferred from 500 replicates was taken to represent the evolutionary history of the taxa analyzed. Branches corresponding to partitions reproduced in less than $50 \%$ bootstrap replicates are collapsed. The evolutionary distances were computed using the Maximum Composite Likelihood method and were in the units of the number of base substitutions per site. The analysis involved 465 nucleotide sequences. All positions containing gaps and missing data were eliminated. There were a total of 958 positions in the final dataset. Label of bacterial strains/species showing values lower than $1 \%$ was hidden. Evolutionary analyses were conducted in MEGA6.0. 


\section{Ecological Significance of ACC Deaminase Bacteria}

The ACC deaminase activity is one of the most common traits among plant growth promoting rhizobacteria (Honma and Shimomura, 1978; Glick, 2005). ACCD bacteria exert its beneficial effect by protecting from the deleterious effect of environmental stressors (Glick, 2014), delay senescence (Ali et al., 2012), exhibit biocontrol activity against variety of phytopathogens in certain plants (Hao et al., 2011), and favor nodulation in legume plants (Nascimento et al., 2012a). Role and importance of bacterial ACCD in plant growth have been described in previous sections. Variation of ACC deaminase activity among microbial species at extreme environmental conditions might be useful in phytoremediation at unusual environmental sites or conditions (Glick, 2005). ACC deaminase bacteria assist associated plants in phytoremediation by biotransformation of toxic elements, rhizodegradation mediated by root exudates, and/or detoxification of heavy metals that allow host plants to survive under adverse conditions. Rhizospheric bacterial community with ACC deaminase can enhance the rate of rhizo-remediation by increasing the root system of the plant as well as increased access to soil by roots. It results in enhanced uptake of inorganic contaminants through modification of root architecture and root uptake system of the plant. Belimov et al. (2005) reported a positive correlation between the increment of bacterial ACC deaminase activity following the accumulation of cadmium in plant tissue and enhanced root growth. Similarly, Rodriguez et al. (2008) observed the enhanced growth of tobacco plants and substantial accumulation of metals from nickel contaminated soil following inoculation of $P$. putida HS-2.

The presence of ACC deaminase in human pathogenic Burkholderia cenocepacia J 2315 as well as in plant pathogenic fungi like Aspergillus spp. and Myceliophthora thermophile suggests that ACC deaminase might play a role in the ecological fitness of these micro-organisms. Role of ACC deaminase in endophytic fungi P. citrinum was investigated by Jia et al. (2000) who found accumulation of ACC during mycelial growth and subsequent degradation of ACC by ACC deaminase when the mycelial growth reached the maximum. Importance of ACCD in human pathogenic bacteria is not known, but its role in the pathogenesis of plant pathogens has been studied to some extent. For plant pathogenic microorganisms, it is assumed that production of ACC deaminase may help microbe to overcome ACC mediated plant responses. The presence of ACC deaminase bacteria in the close vicinity of fungal strains might have a role in increased fungal primordial proliferation by reducing ACC levels. Thus, an association of ACC deaminase bacteria plays a significant role in fungal colonization in the extreme soil. Additional advantage of these bacteria is the ability to degrade ACC providing extra nutrients to plant (Nascimento et al., 2014).

\section{Transgenic Plants with ACC Deaminase Activity}

The growth enhancement of plant by ACC deaminase bacteria has motivated scientists to transfer this gene into plants as future approach to minimize the deleterious effect of ethylene in plants subjected to adverse environmental conditions (Grichko and Glick, 2001; Robison et al., 2001; Nie et al., 2002). A transgenic Petunia hybrid with ACC deaminase gene maintains a significantly reduced amount of ACC in pollen cells (Lei et al., 1996). Similarly, the transgenic canola plants (Brassica napus) with ACC deaminase perform better growth under salinity stress compared to non-transgenic plant (Sergeeva et al., 2006). In a premier study, Reed et al. (1995) transformed two tomato cultivars with AcdS gene of Pseudomonas chlororaphis which resulted in lengthened duration of fruit ripening as well as significant reduction of stress ethylene production compared to parental line. Klee and Kishore (1992) also observed a significant reduction of ethylene production (77\%) and delayed in senescence in tobacco and tomato plants transformed with bacterial AcdS. The tomato plant (Lycopersicon esculentum) expressing AcdS gene of Pseudomonas sp. 6GS exhibited reduced ethylene synthesis up to $90 \%$ (Klee et al., 1991). A large number of transgenic plants with foreign AcdS gene have been genetically engineered to reduce the deleterious ethylene levels in plants (Grichko and Glick, 2000; Robison et al., 2001; Sergeeva et al., 2006; Farwell et al., 2007; Zhang et al., 2008). However, there is a limited report of the performance of transgenic plant containing AcdS gene under field condition (Farwell et al., 2006, 2007). Furthermore, future research should focus on (i) field performance of transgenic plant, (ii) their survival and yield under diverse condition, and (iii) genetic re-arrangement for target gene identification for gene insertion and deletion.

\section{Conclusion and Future Prospects}

Increasing global warming and environmental pollution in the present scenario have highly affected the agricultural production which is confronted with induced stress generated by both biotic and abiotic factors. Bacteria with ACCD activity are able to mediate the enhanced resistance to biotic stressors and increased tolerance to abiotic stresses in their associated plants. Thus, these bacteria have the potential to promote plant growth under adverse environmental conditions. Therefore, it necessitates exploration of efficient PGPB with strong ACCD activity which can colonize plants effectively and increase plant productivity under actual farming conditions. ACCD is an inducible enzyme which expresses on the availability of ACC and regulated differentially by various physiological factors. This enzyme is tightly regulated. However, precise mechanisms of its regulation are understood only in few bacteria. Lack of information about the regulatory mechanism for expression of ACCD gene in the majority of organisms is a major constraint. The understanding regulatory circuit of ACCD gene will be helpful in the optimal exploitation of ACCD bacteria for enhancing plant productivity. Based on current knowledge, a very few plants like Arabidopsis, tomato, poplar have been reported to contain AcdS gene. Therefore, future research needs to explore AcdS gene in other plant species. The role of ACCD in the plant has been evident in fruit development in tomato and other plants. However, their direct role in stress is not well characterized. Therefore, distribution of ACCD gene in different plants and its possible role in stress amelioration needs to be investigated in detail. Development of transgenic plant overexpressing foreign AcdS 
gene could be used to overcome stress ethylene generated through stress conditions. Moreover, the exact role of ACCD in bacteria also needs to be investigated in greater detail. The presence of ACCD gene in bacteria other than plant-associated bacteria intrigues its role and suggests the possibility for an alternative function.

\section{Acknowledgments}

We are grateful to Department of Biotechnology (File No. BT/PR14527/AGR/21/326/2010) Govt. of India, New Delhi for

\section{References}

Abeles, F. B., Morgan, P. W., and Saltveit, M. E. (1992). Ethylene in Plant Biology, 2nd Edn. New York, NY; San Diego, CA: Academic Press.

Ait Bakra, E., Nowak, J., and Clément, C. (2006). Enhancement of chilling resistance of inoculated grapevine plantlets with a plant growth promoting rhizobacterium Burkholderia phytofirmans strain PsJN. Appl. Environ. Microbiol. 72, 7246-7252. doi: 10.1128/AEM.01047-06

Ali, S., Charles, T. C., and Glick, B. R. (2014). Amelioration of high salinity stress damage by plant growth-promoting bacterial endophytes that contain ACC deaminase. Plant Physiol. Biochem. 80, 160-167. doi: 10.1016/j.plaphy.2014.04.003

Ali, S., Charles, T., and Glick, B. R. (2012). Delay of flower senescence by bacterial endophytes expressing 1-aminocyclopropane-1-carboxylate deaminase. J. Appl. Microbiol. 113, 1139-1144. doi: 10.1111/j.1365-2672.2012.05409.x

Arshad, M., and Frankenberger, W. T. (1990). Ethylene accumulation in soil in response to organic amendments. Soil Sci. Soc. Am. J. 54, 1026-1031. doi: 10.2136/sssaj1990.03615995005400040016x

Arshad, M., Shaharoona, B., and Mahmood, T. (2008). Inoculation with Pseudomonas spp. containing ACC-deaminase partially eliminates the effects of drought stress on growth, yield, and ripening of pea (Pisum sativum L.). Pedosphere 18, 611-620. doi: 10.1016/S1002-0160(08) 60055-7

Babalola, O. O., Osir, E. O., Sanni, A. I., Odhiambo, G. D., and Bulimo, W. D. (2003). Amplification of 1-amino-cyclopropane-1-carboxylic (ACC) deaminase from plant growth promoting bacteria in Strigainfested soil. Afr. J. Biotechnol. 2, 157-160. doi: 10.5897/AJB2003. 000-1032

Belimov, A. A., Hontzeas, N., Safronova, V. I., Demchinskaya, S. V., Piluzza, G., Bullitta, S., et al. (2005). Cadmium tolerant plant growthpromoting bacteria associated with roots of Indian mustard (Brassica juncea L Czern.). Soil Biol. Biochem. 37, 241-250. doi: 10.1016/j.soilbio. 2004.07.033

Belimov, A. A., Safronova, V. I., Sergeyeva, T. A., Egorova, T. N., Matveyeva, V. A., Tsyganov, V. E., et al. (2001). Characterization of plant growth promoting rhizobacteria isolated from polluted soils and containing 1aminocyclopropane-1-carboxylate deaminase. Can. J. Microbiol. 47, 242-252. doi: 10.1139/w01-062

Boyer, J. S. (1982). Plant productivity and environment. Science 218, 443-448. doi: 10.1126/science. 218.4571 .443

Bray, E. A., Bailey-Serres, J., and Weretilnyk, E. (2000). "Responses to abiotic stresses," in Biochemistry and Molecular Biology of Plants, eds W. Gruissem, B. Buchannan, and R. Jones (Rockville, MD: American Society of Plant Physiologists), 1158-1249.

Burd, G. I., Dixon, D. G., and Glick, B. R. (1998). A plant growth-promoting bacterium that decreases nickel toxicity in seedlings. Appl. Environ. Microbiol. 64, 3663-3668

Burd, G. I., Dixon, D. G., and Glick, B. R. (2000). Plant growth promoting bacteria that decrease heavy metal toxicity in plants. Can. J. Microbiol. 46, 237-245. doi: $10.1139 / \mathrm{w} 99-143$ their support by providing the fund for carrying out the research work. We acknowledge Dr. Pankaj Sharma, Assistant Professor, Department of Biological Sciences, BITS Pilani, for reviewing and editing scientific content and English language of the text.

\section{Supplementary Material}

The Supplementary Material for this article can be found online at: http://journal.frontiersin.org/article/10.3389/fmicb. 2015.00937

Cheng, Z., Duncker, B. P., McConkey, B. J., and Glick, B. R. (2008) Transcriptional regulation of ACC deaminase gene expression in Pseudomonas putida UW4. Can. J. Microbiol. 54, 128-136. doi: 10.1139/ W07-128

Cheng, Z., Park, E., and Glick, B. R. (2007). 1-Aminocyclopropane-1-carboxylate deaminase from Pseudomonas putida UW4 facilitates the growth of canola in the presence of salt. Can. J. Microbiol. 53, 912-918. doi: 10.1139/ W07-050

Dell'Amico, E., Cavalca, L., and Andreoni, V. (2008). Improvement of Brassica napus growth under cadmium stress by cadmium-resistant rhizobacteria. Soil Biol. Biochem. 40, 74-84. doi: 10.1016/j.soilbio.2007. 06.024

Desbrosses, G., Contesto, C., Varoquaux, F., Galland, M., and Touraine, B. (2009). PGPR-Arabidopsis interaction is an useful system to study signalling pathways involved in plant developmental control. Plant Signal. Behav. 4, 321-323. doi: $10.4161 /$ psb.4.4.8106

Di Gregorio, S., Barbafieri, M., Lampis, S., Sanangelantoni, A. M., Tassi, E., and Vallini, G. (2006). Combined application of Triton X-100 and Sinorhizobium sp. Pb002 inoculum for the improvement of lead phytoextraction by Brassica juncea in EDTA amended soil. Chemosphere 63, 293-299. doi: 10.1016/j.chemosphere.2005.07.020

Duan, J., Jiang, W., Cheng, Z., Heikkila, J. J., and Glick, B. R. (2013). The complete genome sequence of the plant growth-promoting bacterium Pseudomonas sp. UW4. PLoS ONE 8:e58640. doi: 10.1371/journal.pone.00 58640

Duan, J., Müller, K. M., Charles, T. C., Vesely, S., and Glick, B. R. (2009). 1Aminocyclopropane-1- carboxylate (ACC) deaminase genes in Rhizobia from southern Saskatchewan. Microb. Ecol. 57, 423-436. doi: 10.1007/s00248-0089407-6

Farwell, A. J., Vesely, S., Nero, V., Rodriguez, H., McCormack, K., Shah, S., et al. (2006). The use of transgenic canola (Brassica napus) and plant growth-promoting bacteria to enhance plant biomass at a nickelcontaminated field site. Plant Soil 288, 309-318. doi: 10.1007/s11104-0069119-y

Farwell, A. J., Vesely, S., Nero, V., Rodriguez, H., McCormack, K., Shah, S., et al. (2007). Tolerance of transgenic canola plants (Brassica napus) amended with plant growth-promoting bacteria to flooding stress at a metal contaminated field site. Environ. Pollut. 147, 540-545. doi: 10.1016/j.envpol.2006. 10.014

Fujino, A., Ose, T., Yao, M., Tokiwano, T., Honma, M., Watanabe, N., et al. (2004). Structural and enzymatic properties of 1-aminocyclopropane-1-carboxylate deaminase homologue from Pyrococcus horikoshii. J. Mol. Biol. 341, 999-1013 doi: 10.1016/j.jmb.2004.06.062

Gamalero, E., and Glick, B. R. (2012). "Plant growth-promoting bacteria and metal phytoremediation," in Phytotechnologies: Remediation of Environmental Contaminants, eds N. A. Anjum, M.E. Pereira, I. Ahmad, A. C. Duarte, S. Umar, and N. A. Khan (Boca Raton, FL: CRC Press), 361-376.

Ghosh, S., Penterman, J. N., Little, R. D., Chavez, R., and Glick, B. R. (2003). Three newly isolated plant growth-promoting bacilli facilitate the growth of 
canola seedlings. Plant Physiol. Biochem. 41, 277-281. doi: 10.1016/S09819428(03)00019-6

Glick, B. R. (2005). Modulation of plant ethylene levels by the bacterial enzyme ACC deaminase. FEMS Microbiol. Lett. 251, 1-7. doi: 10.1016/j.femsle.2005.07.030

Glick, B. R. (2007). Promotion of plant growth by bacterial ACC deaminase. Crit. Rev. Plant Sci. 26, 227-242. doi: 10.1080/07352680701572966

Glick, B. R. (2014). Bacteria with ACC deaminase can promote plant growth and help to feed the world. Microbiol. Res. 169, 30-39. doi: 10.1016/j.micres.2013.09.009

Glick, B. R., Nascimento, F. X., Vicente, C. S. L., Barbosa, P., Espada, M., Mota, M., et al. (2013). Evidence for the involvement of ACC deaminase from Pseudomonas putida UW4 in the biocontrol of pine wilt disease caused by Bursaphelenchus xylophilus. Biocontrol 58, 427-433. doi: 10.1007/s10526-0129500-0

Glick, B. R., Penrose, D. M., and Li, J. (1998). A model for lowering of plant ethylene concentrations by plant growth promoting bacteria. J. Theoret. Biol. 190, 62-68. doi: 10.1006/jtbi.1997.0532

Grichko, V. P., and Glick, B. R. (2000). Identification of DNA sequences that regulate the expression of the Enterobacter cloaceae UW4 1aminocyclopropane-1-carboxylate deaminase gene. Can. J. Microbiol. 46, 1159-1165. doi: 10.1139/w00-113

Grichko, V. P., and Glick, B. R. (2001). Amelioration of flooding stress by ACC deaminase containing plant growth-promoting bacteria. Plant Physiol. Biochem. 39, 11-17. doi: 10.1016/S0981-9428(00)01212-2

Hao, Y., Charles, T. C., and Glick, B. R. (2011). An ACC deaminase containing A. tumefaciens strain D3 shows biocontrol activity to crown gall disease. Can. J. Microbiol. 57, 278-286. doi: 10.1139/w11-006

Honma, M. (1983). Enzymatic determination of 1-aminocyclopropane1-carboxylate deaminase. Agric. Biol. Chem. 47, 617-618. doi: 10.1271/bbb1961.47.617

Honma, M. (1985). Chemically reactive sulfhydryl groups of 1aminocyclopropane-1-carboxylate deaminase. Agric. Biol. Chem. 49, 567-571. doi: $10.1271 /$ bbb1961.49.567

Honma, M., and Shimomura, T. (1978). Metabolism of 1-aminocyclopropane1-carboxylic acid. Agric. Biol. Chem. 42, 1825-1831. doi: 10.1271/bbb1961.42.1825

Honma, M., Kawai, J., and Yamada, M. (1993). Identification of the sulfhydryl group of 1- aminocyclopropane-1-carboxylate deaminase. Biosci. Biotechnol. Biochem. 57, 2090-3000. doi: 10.1271/bbb.57.2090

Hontzeas, N., Hontzeas, C. E., and Glick, B. R. (2006). Reaction mechanisms of the bacterial enzyme 1-aminocyclopropane-1-carboxylate deaminase. Biotechnol. Adv. 24, 420-426. doi: 10.1016/j.biotechadv.2006.01.006

Hontzeas, N., Richardson, A. O., Belimov, A. A., Safranova, V. I., Abu-Omar, M. M., and Glick, B. R. (2005). Evidence for horizontal gene transfer (HGT) of ACC deaminase genes. Appl. Environ. Microbiol. 71, 7556-7568. doi: 10.1128/AEM.71.11.7556-7558.2005

Hontzeas, N., Zoidakis, J., Glick, B. R., and Abu-Omar, M. M. (2004). Expression and characterization of the 1-aminocyclopropane-1-carboxylic acid deaminase from the rhizobacterium $P$. putida UW4: a key enzyme in bacterial plant growth promotion. Biochim. Biophys. Acta 1703, 11-19. doi: 10.1016/j.bbapap.2004.09.015

Itoh, T., Aiba, H., Baba, T., Hayashi, K., Inada, T., Isono, K., et al. (1996). A 460kb DNA sequence of the Escherichia coli K-12 genome corresponding to the 40.1-50.0 min region on the linkage map (Supplement). DNA Res. 3, 441-445.

Jackson, M. B. (1991). "Ethylene in root growth and development," in The Plant Hormone Ethylene, eds A. K. Matoo and J. C. Suttle (Boca Raton, FL: CRC Press), 159-181.

Jacobson, C. B., Pasternak, J. J., and Glick, B. R. (1994). Partial purification and characterization of 1-aminocyclopropane-1-carboxylate deaminase from the plant growth promoting rhizobacterium Pseudomonas putida GR12-2. Can. J. Microbiol. 40, 1019-1025. doi: 10.1139/m94-162

Jha, B., Gontia, I., and Hartmann, A. (2012). The roots of the halophyte Salicornia brachiata are a source of new halotolerant diazotrophic bacteria with plant growth-promoting potential. Plant Soil 356, 265-277. doi: 10.1007/s11104-0110877-9

Jia, Y. J., Ito, H., Matsui, H., and Honma, M. (2000). 1-Aminocyclopropane-1carboxylate (ACC) deaminase induced by ACC synthesized and accumulated in Penicillium citrinum intracellular spaces. Biosci. Biotechnol. Biochem. 64, 299-305. doi: 10.1271/bbb.64.299

Jia, Y. J., Kakuta, Y., Sugawara, M., Igarashi, T., Oki, N., Kisaki, M., et al. (1999). Synthesis and degradation of 1-aminocyclopropane-1-carboxylic caid by Penicillium citrinum. Biosci. Biotechnol. Biochem. 63, 542-549. doi: 10.1271/bbb.63.542

Jiang, C. Y., Sheng, X. F., Qian, M., and Wang, Q. Y. (2008). Isolation and characterization of a heavy metal resistant Burkholderia sp. from heavy metalcontaminated paddy field soil and its potential in promoting plant growth and heavy metal accumulation in metal polluted soil. Chemosphere 72, 157-164. doi: 10.1016/j.chemosphere.2008.02.006

Kaneko, T., Nakamura, Y., Sato, S., Minamisawa, K., Uchiumi, T., Sasamoto, S., et al. (2002). Complete genome sequence of nitrogen fixing symbiotic bacterium Bradyrhizobium japonicum USDA110. DNA Res. 9, 189-197. doi: 10.1093/dnares/9.6.189

Klee, H. J., and Kishore, G. M. (1992). Control of Fruit Ripening and Senescence in Plants. U.S. Patent Number 5702933. St. Louis, MO: Monsanto.

Klee, H. J., Hayford, M. B., Kretzmer, K. A., Barry, G. F., and Kishore, G. M. (1991). Control of ethylene synthesis by expression of bacterial enzyme in transgenic tomato plants. Plant Cell 3, 1187-1193. doi: 10.1105/tpc.3. 11.1187

Kumar, K. V., Singh, N., Behl, H. M., and Srivastava, S. (2008). Influence of plant growth promoting bacteria and its mutant on heavy metal toxicity in Brassica juncea grown in fly ash amended soil. Chemosphere 72, 678-683. doi: 10.1016/j.chemosphere.2008.03.025

Lei, C. H., Lindstrom, J. T., and Woodson, W. R. (1996). Reduction of 1aminocyclopropane-1-carboxylic acid (ACC) in pollen by expression of ACC deaminase in transgenic Petunias. Plant Physiol. 111, 149.

Li, J., Ovakim, D. H., and Charles, T. C., and Glick, B. R. (2000). An ACC deaminase minus mutant of Enterobacter cloacae UW4 no longer promotes root elongation. Curr. Microbiol. 41, 101-105. doi: 10.1007/s002840010101

Li, J., and Glick, B. R. (2001). Transcriptional regulation of the Enterobactercloaceae UW4 1-aminocyclopropane-1-carboxylate (ACC) deaminase gene (AcdS). Can. J. Microbiol. 47, 259-267. doi: 10.1139/cjm-47-4-359

Ma, W., Charles, T. C., and Glick, B. R. (2004). Expression of an exogenous the 1-aminocyclopropane-1-carboxylic acid deaminase gene in Sinorhizobium meliloti increases its ability to nodulate alfalfa. Appl. Environ. Microbiol. 70, 5891-5897. doi: 10.1023/A:1023360919140

Ma, W., Guinel, F. C., and Glick, B. R. (2003a). Rhizobium leguminosarum biovarviciae 1- aminocyclopropane-1-carboxylate deaminase promotes nodulation of pea plants. Appl. Environ. Microbiol. 69, 4396-4402. doi: 10.1128/AEM.69.8.4396-4402.2003

Ma, W., Sebestianova, S. B., Sebestian, J., Burd, G. I., Guinel, F. C., and Glick, B. R. (2003b). Prevalence of 1-aminocyclopropane-1-carboxylate deaminase in Rhizobium spp. Antonie Van Leeuwenhoek 83, 285-291. doi: 10.1023/A:1023360919140

Madhaiyan, M., Poonguzhali, S., Ryu, J., and Sa, T. (2006). Regulation of ethylene levels in canola (Brassica campestris) by 1-aminocyclopropane-1-carboxylate deaminase-containing Methylobacterium fujisawaense. Planta 224, 268-278. doi: 10.1007/s00425-005-0211-y

Maimaiti, J., Zhang, Y., Yang, J., Cen, Y. P., Layzell, D. B., Peoples, M., et al. (2007). Isolation and characterization of hydrogen oxidizing bacteria induced following exposure of soil to hydrogen gas and their impact on plant growth. Environ. Microbiol. 9, 435-444. doi: 10.1111/j.1462-2920.2006. 01155.x

Mayak, S., Tirosh, T., and Glick, B. R. (1999). Effect of wild-type and mutant plant growth-promoting rhizobacteria on the rooting of mung bean cuttings. J. Plant Growth Regul. 18, 49-53. doi: 10.1007/PL00007047

Mayak, S., Tirosh, T., and Glick, B. R. (2004). Plant growth-promoting bacteria confer resistance in tomato plants to salt stress. Plant Physiol. Biochem. 42, 565-572. doi: 10.1016/j.plaphy.2004.05.009

McDonnell, L., Plett, J. M., Andersson-Gunnerås, S., Kozela, C., Dugardeyn, J., Van Der, S. D., et al. (2009). Ethylene levels are regulated by a plant encoded 1aminocyclopropane-1-carboxylic acid deaminase. Physiol. Plant. 136, 94-109. doi: 10.1111/j.1399-3054.2009.01208.x

Minami, R., Uchiyama, K., Murakami, T., Kawai, J., Mikami, K., Yamada, T., et al. (1998). Properties, sequence, and synthesis in Escherichia coli of 
1- aminocyclopropane-1-carboxylate deaminase from Hansenula saturnus. J. Biochem. 123, 1112-1118.

Nadeem, S. M., Zahir, Z. A., Naveed, M., and Arshad, M. (2007). Preliminary investigations on inducing salt tolerance in maize through inoculation with rhizobacteria containing ACC deaminase activity. Can. J. Microbiol. 53, 1141-1149. doi: 10.1139/W07-081

Nadeem, S. M., Zahir, Z. A., Naveed, M., Asghar, H. N., and Arshad, M. (2010). Rhizobacteria capable of producing ACC-deaminase may mitigate salt stress in wheat. Soil Sci. Soc. Am. J. 74, 533-542. doi: 10.2136/sssaj2008.0240

Nascimento, F. X., Brígido, C., Glick, B. R., and Oliveira, S. (2012b). ACC deaminase genes are conserved between Mesorhizobium species able to nodulate the same host plant. FEMS Microbiol. Lett. 336, 26-37. doi: 10.1111/j.1574-6968.2012.02648.x

Nascimento, F. X., Rossi, M. J., Soares, C. R. F. S., McConkey, B. J., and Glick, B. R. (2014). New insights into 1-aminocyclopropane-1-carboxylate (ACC) deaminase phylogeny, evolution and ecological significance. PLoS ONE 9:e99168. doi: 10.1371/journal.pone.0099168

Nascimento, F. X., Vicente, C. S. L., Barbosa, P., Espada, M., Glick, B. R., Oliveira, S., et al. (2013). The use of the ACC deaminase producing bacterium Pseudomonas putida UW4 as a biocontrol agent for pine wilt disease. Biocontrol 58, 427-433. doi: 10.1007/s10526-012-9500-0

Nascimento, F., Brígido, C., Glick, B. R., Oliveira, S., and Alho, L. (2012a). Mesorhizobium ciceri LMS-1 expressing an exogenous 1-aminocyclopropane1-carboxylate (ACC) deaminase increases its nodulation abilities and chickpea plant resistance to soil constraints. Lett. Appl. Microbiol. 55, 15-21. doi: 10.1111/j.1472-765X.2012.03251.x

Nie, L., Shah, S., Rashid, A., Burd, G. I., Dixon, D. G., and Glick, B. R. (2002). Phytoremediation of arsenate contaminated soil by transgenic canola and the plant growth promoting bacterium Enterobacter cloaceae CAL2. Plant Physiol. Biochem. 40, 355-361. doi: 10.1016/S0981-9428(02) 01375-X

Nukui, N., Minamisawa, K., Ayabe, S. I., and Aoki, T. (2006). Expression of the 1-aminocyclopropane-1-carboxylic acid deaminase gene requires symbiotic nitrogen fixing regulator gene nifA2 in Mesorhizobium loti MAFF303099. Appl. Environ. Microbiol. 72, 4964-4969. doi: 10.1128/AEM.02745-05

Ortíz-Castro, R., Contreras-Cornejo, H. A., Macías-Rodríguez, L., and LópezBucio, J. (2009). The role of microbial signals in plant growth and development. Plant Signal. Behav. 4, 701-712. doi: 10.4161/psb.4.8.9047

Ose, T., Fujino, A., Yao, M., Watanabe, N., Honma, M., and Tanaka, I. (2003). Reaction intermediate structures of 1-aminocyclopropane-1carboxylate deaminase: insight into PLP-dependent cyclopropane ringopening reaction. J. Biol. Chem. 278, 41069-41076. doi: 10.1074/jbc.M3058 65200

Palmer, C., Golden, K., Danniels, L., and Ahmad, H. (2007). ACC deaminase from Issatchenkia occidentalis. J. Biol. Sci. 7, 188-193. doi: 10.3923/jbs.2007.188.193

Pierik, R., Tholen, D., Poorter, H., Visser, E. J. W., and Voesenek, L. A. C. J. (2006). The Janus face of ethylene: growth inhibition and stimulation. Trends Plant Sci. 11, 176-183. doi: 10.1016/j.tplants.2006.02.006

Plett, J. M., McDonnell, L., and Regan, S. (2009). Plant encoded 1aminocyclopropane-1-carboxylic acid deaminase activity implicated in different aspects of plant development. Plant Signal. Behav. 4, 1186-1189. doi: $10.4161 /$ psb.4.12.10060

Prigent-Combaret, C., Blaha, D., Pothier, J. F., Vial, L., Poirier, M. A., WisniewskiDye, F., et al. (2008). Physical organization and phylogenetic analysis of $a c d R$ as leucine responsive regulator of the 1-aminocyclopropane-1-carboxylate deaminase gene acdS in phytobeneficial in Azospirillum lipoferum $4 \mathrm{~B}$ and other Proteobacteria. FEMS Microbiol. Ecol. 65, 202-219. doi: 10.1111/j.15746941.2008.00474.x

Rashid, S., Charles, T. C., and Glick, B. R. (2012). Isolation and characterization of new plant growth-promoting bacterial endophytes. Agric. Ecosyst. Environ. 61, 217-224. doi: 10.1016/j.apsoil.2011.09.011

Reed, A. J., Magin, K. M., Anderson, J. S., Austin, G. D., Rangwala, T., Linde, D. C., et al. (1995). Delayed ripening in tomato plants expressing the enzyme 1aminocyclopropane-1-carboxylic acid deaminase: molecular characterization, enzyme expression, and fruit ripening traits. J. Agric. Food Chem. 43, 1954-1962. doi: 10.1021/jf00055a036

Riemenschneider, A., Wegele, R., Schmidt, A., and Papenbrock, J. (2005). Isolation and characterization of a D-cysteine desulfhydrase protein from
Arabidopsis thaliana. FEBS J. 272, 1291-1304. doi: 10.1111/j.1742-4658.2005. 04567.x

Robison, M. M., Griffith, M., Pauls, K. P., and Glick, B. R. (2001). Dual role of ethylene in susceptibility of tomato to Verticillium wilt. J. Phytopathol. 149, 385-388. doi: 10.1046/j.1439-0434.2001.00639.x

Rodriguez, H., Vessely, S., Shah, S., and Glick, B. R. (2008). Effect of a Nickel-tolerant ACC deaminase-producing Pseudomonas strain on growth of nontransformed and transgenic canola plants. Curr. Microbiol. 57, 170-174. doi: 10.1007/s00284-008-9181-1

Saravanakumar, D., and Samiyappan, R. (2007). Effects of 1-aminocyclopropane1-carboxylic acid (ACC) deaminase from Pseudomonas fluorescence against saline stress under in vitro and field conditions in groundnut (Arachis hypogeal) plants. J. Appl. Microbiol. 102, 1283-1292. doi: 10.1111/j.13652672.2006.03179.x

Sergeeva, E., Shah, S., and Glick, B. R. (2006). Growth of transgenic canola (Brassica napus cv. Westar) expressing a bacterial 1-aminocyclopropane-1-carboxylate (ACC) deaminase gene on high concentrations of salt. World J. Microbiol. Biotech. 22, 277-282. doi: 10.1007/s11274-005-9032-1

Sessitsch, A., Howieson, J. G., Perret, X., Antoun, H., and Martinez-Romero, E. (2002). Advances in Rhizobium research. Crit. Rev. Plant Sci. 21, 323-378. doi: 10.1080/0735-260291044278

Shah, S., Li, J., Moffatt, B. A., and Glick, B. R. (1998). Isolation and characterization of ACC deaminase genes from two different plant growth promoting rhizobacteria. Can. J. Microbiol. 44, 833-843. doi: 10.1139/ w98-074

Shaharoona, B., Arshad, M., and Zahir, Z. A. (2006a). Effect of plant growth promoting rhizobacteria containing ACC-deaminase on maize (Zea mays L.) growth under axenic conditions and on nodulation in mung bean (Vigna radiata L.). Lett. Appl. Microbiol. 42, 155-159. doi: 10.1111/j.1472765X.2005.01827.x

Shaharoona, B., Jamro, G. M., Zahir, Z. A., Arshad, M., and Memon, K. S. (2007b). Effectiveness of various Pseudomonas spp., and Burkholderia caryophylli containing ACC-deaminase for improving growth and yield of wheat (Triticum aestivum L.). J. Microbiol. Biotechnol. 17, 1300-1307.

Singh, N., and Kashyap, S. (2012). In-silico identification and characterization of 1-aminocyclopropane-1-carboxylate deaminase from Phytophthora sojae. J. Mol. Model. 18, 4101-4111. doi: 10.1007/s00894-0121389-0

Tak, H. I., Ahmad, F. and Babalola, O. O. (2013). Advances in the application of plant growth-promoting rhizobacteria in phytoremediation of heavy metals. Rev. Environ. Contam. Toxicol. 223, 33-52. doi: 10.1007/978-1-4614-5577-6_2

Tilman, D., Cassman, K. G., Matson, P. A., Naylor, R., and Polasky, S. (2002). Agricultural sustainability and intensive production practices. Nature 418, 671-677. doi: 10.1038/nature01014

Timmusk, S., Paalme, V., Pavlicek, T., Bergquist, J., Vangaia, A., Danilas, T., et al. (2011). Bacterial distribution in the rhizosphere of wild barley under contrasting microclimates. PLOS ONE 6:e17968. doi: 10.1371/journal.pone.0017968

Trott, S., Bauer, R., Knackmuss, H. J., and Stolz, A. (2001). Genetic and biochemical characterization of an enantio selective amidase from Agrobacterium tumefaciens strain d3. Microbiology 147, 1815-1824. doi: 10.1099/00221287$147-7-1815$

Uchiumi, T., Oowada, T., Itakura, M., Mitsui, H., Nukui, N., Dawadi, P., et al. (2004). Expression islands clustered on symbiosis island of Mesorhizobium loti genome. J. Bacteriol. 186, 2439-2448. doi: 10.1128/JB.186.8.2439-2448.2004

Van Loon, L. C., Geraats, B. P. J., and Linthorst, H. J. M. (2006). Ethylene as a modulator of disease resistance in 916 plants. Trends Plant Sci. 11, 184-191. doi: 10.1016/j.tplants.2006.02.005

Viterbo, A., Landau, U., Kim, S., Chernin, L., and Chet, I. (2010). Characterization of ACC deaminase from the biocontrol and plant growth-promoting agent Trichoderma asperellum T203. FEMS Microbiol. Lett. 305, 42-48. doi: 10.1111/j.1574-6968.2010.01910.x

Walsh, C., Pascal, R. A., Hohnston, M., Raines, R., Dikshit, D., Krantz, A., et al. (1981). Mechanistic studies on the pyridoxal phosphate enzyme 1- aminocyclopropane-1-carboxylate deaminase form Pseudomonas sp. Biochemistry 20, 7509-7519. doi: 10.1021/bi00529a028

Wand, C., Ramette, A., Punjasamarnwong, P., Zala, M., Natsch, A. Moenne-Loccoz, Y., et al. (2001). Cosmopolitan distribution of 
phlD-containing dicotyledonous crop associated biological control Pseudomonas of worldwide origin. FEMS Microbiol. Ecol. 37, 105-116. doi: 10.1111/j.1574-6941.2001.tb00858.x

Wang, C., Knill, E., Glick, B. R., and Défago, G. (2000). Effect of transferring 1-aminocyclopropane-1-carboxylic acid (ACC) deaminase genes into Pseudomonas fluorescens strain CHAO and its gacA derivative CHA96 on their growth-promoting and disease-suppressive capacities. Can. J. Microbiol. 46, 898-907. doi: 10.1139/cjm-46-10-898

Yan, J., Smith, M. D., Glick, B. R., and Liang, Y. (2014). Effects of ACC deaminase containing rhizobacteria on plant growth and expression of Toc GTPases in tomato (Solanum lycopersicum) under salt stress. Botany 92, 775-781. doi: 10.1139/cjb-2014-0038

Yang, J., Kloepper, J. W., and Ryu, C. M. (2009). Rhizosphere bacteria help plants tolerate abiotic stress. Trends Plant Sci. 14, 1-4. doi: 10.1016/j.tplants.2008.10.004

Zahir, Z. A., Ghani, U., Naveed, M., Nadeem, S. M., and Asghar, H. N. (2009). Comparative effectiveness of Pseudomonas and Serratia sp. containing ACCdeaminase for improving growth and yield of wheat (Triticum aestivum L.) under salt-stressed conditions. Arch. Microbiol. 191, 415-424. doi: 10.1007/s00203-009-0466-y

Zahir, Z. A., Munir, A., Asghar, H. N., Shaharoona, B., and Arshad, M. (2008). Effectiveness of rhizobacteria containing ACC deaminase for growth promotion of peas (Pisum sativum) under drought conditions. J. Microbiol. Biotechnol. 18, 958-963.

Zhang, Y., Zhao, L., Wang, Y., Yang, B., and Chen, S. (2008). Enhancement of heavy metal accumulation by tissue specific coexpression of iaaM and ACC deaminase genes in plants. Chemosphere 72, 564-571. doi: 10.1016/j.chemosphere.2008.03.043

Zhao, H., Chen, K., Li, K., Du, W., He, S., and Liu, H. W. (2003). Reaction of 1-amino-2-methylenecyclopropane-1-carboxylate with 1aminocyclopropane-1-carboxylate deaminase: analysis and mechanistic implications. Biochemistry 42, 2089-2103. doi: 10.1021/bi02 $0567 \mathrm{n}$

Conflict of Interest Statement: The authors declare that the research was conducted in the absence of any commercial or financial relationships that could be construed as a potential conflict of interest.

Copyright (c) 2015 Singh, Shelke, Kumar and Jha. This is an open-access article distributed under the terms of the Creative Commons Attribution License (CC BY). The use, distribution or reproduction in other forums is permitted, provided the original author(s) or licensor are credited and that the original publication in this journal is cited, in accordance with accepted academic practice. No use, distribution or reproduction is permitted which does not comply with these terms. 